\title{
Mitochondrial phylogeny and comparative mitogenomics of closely related pine moth pests (Lepidoptera: Dendrolimus)
}

\author{
Jie Qin ${ }^{\text {Equal first author, } 1}$, Jing Li ${ }^{\text {Equal first author, } 1}$, Qiang Gao ${ }^{2}$, John James Wilson ${ }^{3}$, Ai-bing Zhang ${ }^{\text {Corresp. } 1}$ \\ ${ }^{1}$ College of Life Sciences, Capital Normal University, Beijing, P. R. China. \\ 2 Institute of Genetics and Developmental Biology, Chinese Academy of Sciences, Beijing, P. R. China \\ 3 International College Beijing, China Agricultural University, Beijing, P. R. China \\ Corresponding Author: Ai-bing Zhang \\ Email address: zhangab2008@mail.cnu.edu.cn
}

Background. Pine moths, Dendrolimus spp. (Lasiocampidae), are serious economic pests of conifer forests. Six closely related species (Dendrolimus punctatus, D. tabulaeformis, D. spectabilis, D. superans, D. houi, and D. kikuchii) occur in China and cause serious damage to coniferophyte. The complete mito genomes of Dendrolimus genus are significant to resolve the phylogenetic relationship and provide theoretical support in pest control.

Methods. The complete mitogenomes of 3 species (D. superans, D. houi and D. kikuchii) were sequenced based on PCR-amplified with universal primers, which were used to amplify initial fragments. Phylogenetic analyses were carried out with 78 complete mitogenomes of lepidopteran species from 10 superfamilies.

Results. The complete mitochondrial genomes of these 3 species were 15,417 bp, 15,381bp and15,377bp in length, separately. The phylogenetic analyses produced consistent results for six Dendrolimus species based on complete mitogenomes, two major clades were formed, one containing $D$. spectabilis clustered with $D$. punctatus $+D$. tabulaeformis, and $D$. superans as the sister group to this three-taxon clade, the other containing $D$. kikuchii and $D$. houi. Comparative analyses of the congeneric mitochondrial genomes were performed, which showed that non-coding regions were more variable than the A+T rich region. The mitochondrial nucleotide diversity was more variable when compared within than among genus, and the concatenated tRNA region was the most conserved and the nd6 genes was the most variable. 
1 Mitochondrial phylogeny and comparative mitogenomics of closely related pine

2 moth pests (Lepidoptera: Dendrolimus)

3

4 Jie Qin ${ }^{1 \dagger}$, Jing $\mathrm{Li}^{1 \dagger}$, Qiang $\mathrm{Gao}^{2}$, John James Wilson ${ }^{3}$, Ai-bing Zhang ${ }^{1 *}$

$5 \uparrow$ Note: These authors equally contributed to the work.

$6 \quad{ }^{1}$ College of Life Sciences, Capital Normal University, Beijing, P. R. China.

$7 \quad{ }^{2}$ Institute of Genetics and Developmental Biology, Chinese Academy of Sciences, Beijing, P. R.

8 China.

$9 \quad{ }^{3}$ International College Beijing, China Agricultural University, Beijing, P. R. China.

* Corresponding Author:

Ai-bing Zhang ${ }^{1}$

105 West Third Ring Road North, Haidian District, Beijing, 100048, P. R. China.

Email address: zhangab2008@mail.cnu.edu.cn

\section{Abstract}

Background. Pine moths, Dendrolimus spp. (Lasiocampidae), are serious economic pests of conifer forests. Six closely related species (Dendrolimus punctatus, D. tabulaeformis, D. spectabilis, D. superans, D. houi, and D. kikuchii) occur in China and cause serious damage to coniferophyte. The complete mitogenomes of Dendrolimus genus are significant to resolve the phylogenetic relationship and provide theoretical support in pest control.

Methods. The complete mitogenomes of 3 species (D. superans, D. houi and D. kikuchii) were sequenced based on PCR-amplified with universal primers, which were used to amplify initial fragments. Phylogenetic analyses were carried out with 78 complete mitogenomes of lepidopteran species from 10 superfamilies.

Results. The complete mitochondrial genomes of these 3 species were 15,417 bp, 15,381bp and15,377bp in length, separately. The phylogenetic analyses produced consistent results for six Dendrolimus species based on complete mitogenomes, two major clades were formed, one containing D. spectabilis clustered with D. punctatus + D. tabulaeformis, and D. superans as the sister group to this three-taxon clade, the other containing D. kikuchii and D. houi. Comparative 
analyses of the congeneric mitochondrial genomes were performed, which showed that non-coding regions were more variable than the $\mathrm{A}+\mathrm{T}$ rich region. The mitochondrial nucleotide diversity was more variable when compared within than among genus, and the concatenated tRNA region was the most conserved and the nd6 genes was the most variable.

\section{Introduction}

Pine moths in the genus Dendrolimus (Lasiocampidae) are major economic pests of coniferous trees, such as Pinus, Larix, Picea and Abies. The caterpillars feed extensively on conifer needles; the resulting damage may reduce the tree's seed yield and can lead to heavy defoliation, dieback, and death (Hou, 1987; Chen, 1990; Liu \& Wu, 2006; Zhang et al., 2003). During an outbreak period, a pine tree can be consumed in a few days, causing withering and death of pine forests on a large-scale. Furthermore, direct contact with living or dead caterpillars, even their pupae, results in poisoning known as caterpillar arthritis, with serious consequences for human health (Hou, 1987). About 30 species of Dendrolimus are known to occur in Eurasia, six of them (D. houi, D. kikuchii, D. punctatus, D. spectabilis, D. superans, D. tabulaeformis) are widely distributed in China (Hou, 1987; Chen, 1990). Meanwhile, D. pini was widely distributed across Europe, Central Asia, and North Africa and D. sibiricus was mainly detected in western Russia (Diaz, 2005; Baranchikov et al., 2006; Mikkola and Ståhla, 2008).These species are closely related and their discrimination is challenging (Zhang, Kong \& Li, 2004; Mikkola \& Ståhla, 2008). Taxonomy and phylogenetic relationships of Dendrolimus were not entirely established, and there are many species with a controversial taxonomic position. Not only that, the co-existence of different species of these pine moths and natural hybrids lead to great difficulties for the species identification. Morphological diagnoses have proven difficult because many of the characters commonly used to distinguish pine moth species are non-discrete and overlapping amongst the species. Furthermore, some Dendrolimus species are sympatric coexistence and sharing similar host plants (Tsai \& Liu, 1962). Hybridization experiments and several molecular studies have been conducted, but no consensus has been achieved regarding their species status (Zhao et al., 1992; Mikkola \& Ståhla, 2008; Dai et al., 2012; Zhang et al., 2014; Kononov et al., 2016). 
Mitochondrial genomes (mitogenomes) have been widely used in phylogenetic, population genetics and comparative genomics studies (Wilson et al., 2000; Simon et al., 2006; Salvato et al., 2008; Cameron, 2014; Qin et al., 2015). Insect mitogenomes have relatively stable structure, such as double-stranded, circular DNA molecule, 14-20 kb in size, comprising 37 genes including 13 protein-coding genes (Boore, 1999). Due to its nature of maternal inheritance, mitogenomes has a fast rate of evolution and is particularly useful in phylogenetic analysis (Hebert, Cywinska \& Ball, 2003). In addition, whole mitogenome sequences can also provide sets of genome-level characters, such as the relative position of different genes, structural genomic features and compositional features, which could be quite useful in phylogenetic analysis (Thao, Baumann \& Baumann,2004; Masta \& Boore, 2008).

Whole mitogenomes instead of several separated gene fragments have been used extensively to construct phylogenies, which providing higher support levels (Boore, 2006; Yang et al., 2015). Within the order Lepidoptera, multiple studies have used mitogenomes to reconstruct the phylogenetic relationships among and within superfamilies (Whiting et al., 1997; Yang et al., 2009; Timmermans, Lees \& Simonsen, 2014). Technological advancements have triggered rapid increases in the amount of whole mitogenomes, up to 500 of insect mitogenome have been deposited in GenBank (Timmermans, Lees \& Simonsen, 2014). However, one of the most recent report shows that only 140 complete Lepidoptera mitogenomes (28 families from 12 superfamilies) have been sequenced, and only 64 are available for moth species (Ramírez-Ríos et al., 2016). The ease and decreased cost of obtaining whole mitogenome sequences has provided the possibility of comparative genomic studies across short evolutionary distances (i.e., congeneric) (Curole \& Kocher, 1999) providing an understanding of evolutionary dynamics and trends in a phylogenetic framework.

In this study, six complete mitogenomes from three species (D. superans, D. houi and D. kikuchii, 2 individuals per species) were newly sequenced. These were combined with the complete mitogenomes of three other species (D. punctatus, D. tabulaeformis, D. spectabilis), which have been published previously (Qin et al., 2015), to investigate the taxonomic status of 
86

87

88

89

90

91

92

93

94

95

96

107

108

109

110

111

112

species in the genus Dendrolimus. To place the relationships of the genus Dendrolimus within a broader context, we also conducted phylogenetic analyses of mitogenomes from other lepidopteran species (mainly moth species). In order to investigate the evolutionary dynamics among six Dendrolimus species, comparative analyses were conducted based on 14 mitogenomes (including 2 subspecies of $D$. punctatus), comparing nucleotide composition, codon usage, differences of overlap and non-coding regions.

\section{Materials \& Methods}

Sample collection, DNA extraction, PCR amplification, sequencing, sequence assembly and annotation

Adult pine moth specimens were sampled at four locations in China, including Inner Mongolia, Yunnan and Guizhou provinces (Table 1). All specimens were preserved in 95\% ethanol in the field and stored at $4^{\circ} \mathrm{C}$ in the laboratory until DNA extraction. The specimens were identified by Chun-sheng $\mathrm{Wu}$, Institute of Zoology, Chinese Academy of Sciences, China, using morphological characters. Six individuals of three species (D. kikuchii, D. houi and D. superans, 2 individuals for each species) were selected for sequencing in this study. Total genomic DNA was extracted from thoracic muscle tissue and leg muscle tissue using a DNeasy BLOOD and Tissue kit (QIAGEN) following the manufacturer's protocol.

Mitochondrial genomes were PCR-amplified and sequenced as described in our previous study (Qin et al., 2015). In brief, universal primers were used to amplify initial fragments. Specific fragments were then designed to amplify overlapping regions (i.e. primer walking) (Salvato et al., 2008; Gissi, Iannelli \& Pesole, 2008). PCR recipes and conditions followed Qin et al. (2015). All reactions were performed using Takara LA taq (TaKaRa Co., Dalian, China). PCR fragments containing the control region were cloned into the pEASY-T3 Cloning Vector (Beijing TransGen Biotech Co., Ltd., Beijing, China) and then sequenced by using tailed primers, M13-F (CGCCAGGGTTTTCCCAGTCACGAC) and M13-R (GAGCGGA_TAACAATTT CACACAGG) primers. 
113

114

115

116

117

118

119

120

121

122

123

124

125

126

127

128

129

130

131

132

133

134

135

136

137

138

139

Raw sequences were checked manually and assembled on the basis of overlapping regions with the Bioedit V7.0.5 (Caredata.com, Inc.). The tRNA genes were identified by tRNAscan-SE Search Server v.1.21 (Simon et al., 1994). Protein-coding and rRNA genes were determined by comparing homologous sequences with other published Lepidoptera mitochondrial genomes (following (Qin et al., 2015)). The sequence data have been deposited in GenBank under accession numbers (KY000409 - KY000414).

\section{Phylogenetic analysis}

To place the relationships of the genus Dendrolimus within a broader context, we reconstructed the phylogenetic tree of mitogenomes from other 64 lepidopteran species (mainly moth species). On the other hand, in order to investigate the phylogenetic status of Lasiocampoidea, comparative analyses were conducted based on 14 mitogenomes (including 6 species) of Lasiocampoidea and 13 mitogenomes of Bombycoidea. Other than the six mitogenomes obtained in this study, other complete mitogenomes were mined from Genbank representing lepidopteran species from 10 superfamilies (Supplemental Information 1). Moreover, in order to clarify the relationship between D. superans and D. sibiricus, the COI and COII sequences of D. sibiricus (GenBank No. KJ007773, KJ007800, KJ007771 and KJ007815) were used as supplement data to reconstructed phylogenetic tree, which was carried out based on 13 protein-coding genes (PCGs) with maximum likelihood (ML) method.

Nucleotide sequences of the 13 protein-coding genes were aligned based on the translated amino acid sequences using a customized perl script. Non-protein coding region were aligned using MUSCLE with default settings (Edgar, 2004). The separated genes and partitions were concatenated with SequenceMatrix software (Vaidya, Lohman \& Meier, 2011). The concatenated sets of nucleotides were organized into two datasets: dataset 1 representing the 13 protein-coding genes (PCGs) only and dataset 2 representing 37 genes (13 PCGs + 22 transfer RNA genes (tRNA) +2 ribosomal RNA genes (rRNA)). Substitution saturations of 2 datasets were tested with software DAMBE (Xia \& Xie, 2001), and both datasets were used in phylogenetic analyses, under the optimality criteria of ML and Bayesian inference (BI) (Ronquist \& Huelsenbeck, 2003). 
In order to standardize the partitioning strategy as recommended for phylogenetic analyses

141

142

143

144

145

146

147

148

149

150

151

152

153

154

155

156

157

158

159

160

161

162

163

164

165

166

with mitogenomes (Zardoya \& Meyer, 1996), PartitionFinder v1.1.1software was used to select the optimal partitioning scheme and to find the best-fitting substitution model for each partition under the Bayesian Information Criterion (Lanfear et al., 2012). Not only that, optimized nucleotide substitution models could avoid being affected by the long branch attraction to some extent (Bergsten, 2005). The maximum possible partition scheme was 15 partitions: each proteincoding gene as a separate partition, the concatenated 22 tRNA genes and the concatenated rRNA genes).

ML analysis was performed with RAxML v7.9.6 and BI analysis with a parallel version of MrBayes v 3.2.2 (Stamatakis, 2006; Ronquist et al., 2012). The GTR+G+I model was selected for each partition in the two datasets. Support values for the ML topologies were evaluated via bootstrap tests with 1000 iterations (in RaxML). BI analysis was conducted with two sets of four independent Markov chains run for 10 million Metropolis-coupled (MCMC) generations, with tree sampling occurring every 1000 generations, and burn-in set to $25 \%$ of the trees. After 10 million generations, all runs reached stationary as determined by the program Tracer v1.5.0 (Rambaut \& Drummond, 2007).

\section{Genetic distance analysis among closely related species of Dendrolimus}

In order to test the intraspecific and interspecific differentiation of Dendrolimus, 14 mitogenomic were used to calculate the genetic distance across the two datasets described above, which including two subspecies of D. punctatus (D. punctatus punctatus and D. punctatus wenshanensis) and other 5 species. Genetic distances were calculated using the GTR model selected as the best model by AIC (Akaike information criterion) which performed with Modeltest 3.7 (Posada \& Buckley, 2004; Ronquist et al., 2012). Genetic distances were calculated using a custom C++ script that uses the bio++ function library (Guéguen et al., 2013). A correlation matrix was also estimated according to obtained genetic distance matrix. Correlation values ranged from -1 to 1 , where values closer to 1 are indicative of a closer relationship. A graphical visualization of the genetic distances and correlation matrix was drawn using the corrplot.mixed function in R package (Wei, 2013). 
167

168

169

170

171

172

173

174

175

176

177

178

179

180

181

182

183

184

185

186

187

188

189

190

191

192

193

\section{Comparative mitogenome analyses of Dendrolimus}

Nucleotide composition, codon usage (excluding stop codons) and Relative Synonymous Codon Usage (RSCU) were calculated across 14 mitogenomes of Dendrolimus with MEGA 5.0 (Tamura, 2011). Composition skew was calculated using the formulae: AT skew $=(A-T) /(A+T)$ and GC skew $=(\mathrm{G}-\mathrm{C}) /(\mathrm{G}+\mathrm{C})($ Perna \& Koche, 1995). Sliding window analyses were used to calculate nucleotide diversity values across protein-coding genes and regions, which executed with DnaSP software (Librado \& Rozas, 2009). The window size and step size were set to $100 \mathrm{bp}$ and 25bp, separately.

\section{Results}

\section{Phylogenetic analyses of Lasiocampoidea}

In the phylogenetic analyses of 78 moth mitogenomes, the monophyly of each superfamily was generally well-supported, in which Lasiocampoidea and Bombycoidea were monophyletic and clustered together as sister groups with high support (Figure 1 and 2). Similar trees were obtained based on both two datasets (13PCGs and 37 genes), the only difference was among the superfamilies Bombycoidea, Geometroidea, Lasiocampoidea and Noctuoidea, which altogether constitute approximately 73,000 described species (Minet, 1991). The 13 PCGs dataset phylogeny placed Geometroidea with Bombycoidea and Lasiocampoidea, and Noctuoidea as the sister group to this three-taxon clade (53\% BP support and 0.78 posterior probabilities) (Figure 1), which revealed similar relationship with a prior study (van Nieukerken et al., 2011). Nonetheless, the 37 gene dataset phylogeny (Supplemental Information 2) placed Bombycoidea + Lasiocampoidea as the sister group to Geometroidea + Noctuoidea with higher branch support (100\% BP support and 1.0 posterior probabilities). The latter relationship was demonstrated with morphological and multigenetic proofs (van Nieukerken et al., 1758; Regier et al., 2009; Bazinet et al., 2013; Kawahara \& Breinholt, 2014).

\section{Phylogenetic and genetic distance analyses of Dendrolimus}

Phylogenetic analyses of Dendrolimus resulted in a fully resolved tree with robust support for 
194

195

196

197

198

199

200

201

202

203

204

205

206

207

208

209

210

211

212

213

214

215

216

217

218

219

220

nearly all nodes (Figure 1 and 2). Phylogenetic analyses inferred from different datasets exhibited the same topology. Six species formed two major clades: D. punctatus + D. tabulaeformis $+D$. spectabilis + D. superans (Clade 1) was the sister group to D. kikuchii and D. houi (Clade 2). Within 'Clade 1', D. spectabilis clustered with D. punctatus + D. tabulaeformis, and D. superans was the sister group to this three-taxon clade (Figure 1A). Among six morphospecies, D. superans was successfully found as monophyletic species of these three species (D. tabulaeformis, $D$. punctatus, and D. spectabilis), which was also confirmed by the results based on COI, COII and ribosomal internal transcribed spacer (ITS) (Dai et al., 2012; Kononov et al., 2016). Different from the previous view that $D$. sibiricus was a subspecies of $D$. superans (Liu and Wu, 2016), Kononov et al. (2016) demonstrate that D. sibiricus and D. superans were clearly distinguished from each other based on the phylogenetic analysis of ITS2 sequences. According to the phylogenetic analyses inferred from COI and COII sequences, D. sibiricus and D. superans were closed related species (Figure 1B). However, the taxonomic status of D. sibiricus was still ambiguous and more data from nuclear markers were required.

The genetic distance analyses produced results which were consistent with the results of the phylogenetic analyses. The correlation values obtained from genetic distance analysis among specimens of Dendrolimus showed that in many cases intraspecific and interspecific values were very similar. Values for intraspecific and interspecific correlations in the group comprising $D$. tabulaeformis and two subspecies of $D$. punctatus were equal or very close to 1 , which suggests these sequences all have quite a few differences, which would generally be regarded within the range of intraspecific variation. To illustrate the relationship of Dendrolimus more clearly, we recalculated genetic distance with considered D. punctatus and D. tabulaeformis as an integral taxon (Group A). The genetic distance between D. spectabilis and Group A were 0.05, whereas D. superans and Group A were 0.07 (Figure 2). Furthermore, both the correlation value between $D$. houi - Group A and D. kikuchii - Group A were negative, highlighting the relatively distant genetic relationship with other four species (D. punctatus, D. tabulaeformis, D. spectabilis and D. superans) (Figure 3). 
221 Comparative mitochondrial genome characterization of Dendrolimus

222 (i)

Mitochondrial genome organization

223 The complete mitochondrial genomes of Dendromlius ranged from 15,370 to $15,417 \mathrm{bp}$ in length

224 (Table 2). The gene order was identical to other ditrysian lepidopterans with the standard trnM

225

226

227

228

229

230

231

232

233

234

235

236

237

238

239

240

241

242

243

244

245

246

247

gene location type (trnM-trnI-trnQ), and all mitochondrial genomes exhibit similar sequence characteristics. The mitochondrial genes of three newly-sequenced Dendrolimus species (D. superans, D. houi and D. kikuchii) are coded on the majority strand, except for four protein-coding gene (nd5, nd4, $n d 4 L$ and $n d 1)$ and eight tRNA genes (trnQ, trnC, trnY, trnF, trnH, trnP, $\operatorname{trn} L(C U N)$, and trnV) (Table 2).

\section{Base composition and skewness}

Metazoan mitogenomes usually exhibit a clear strand bias toward adenine (A) and thymine (T) in nucleotide composition. Consistent with previous observations of Dendrolimus mitogenomes, the mitochondrial sequence of three newly-sequenced Dendrolimus species were biased toward A and $\mathrm{T}$. The $\mathrm{A}+\mathrm{T}$ content of the majority strand ranged from $78.7 \%$ and $78.8 \%$ for $D$. kikuchii, $80 \%$ and $79.9 \%$ for D. houi, and $80.1 \%$ and $80.2 \%$ for D. superans (Supplemental Information 3). The strand bias also can be measured as AT- and GC-skews. The average AT-skew across all available Dendrolimus mitochondrial genomes was 0.028 , ranging from 0.037 to 0.017 , whereas the average GC-skew of the Dendrolimus mitochondrial genomes was -0.23 , ranging from -0.26 to -0.22 .

(iii) Start and stop codon usage

Start and stop codon usage is an important characteristic in the annotation of protein-coding genes. We compared the start and stop codons across the six species of Dendrolimus (Table 3). All protein-coding genes started with the typical ATN codons except for coxl which used CGA. Most of the start codon were consistent within the six species but a few were different (nd2, cox2, atp8, $n d 3, n d 5, n d 1)$. This was especially the case for atp8 and nad3, which were the most variable among the genes. It is noteworthy that atp 8 and nad 3 are the shortest protein-coding genes when compare to others in the mitochondrial genome, suggesting variability in start codon usage maybe related to gene length.

Peer] reviewing PDF | (2019:02:35083:1:1:NEW 31 May 2019) 
248

249

250

251

252

253

254

255

256

257

258

259

260

261

262

263

264

265

266

267

268

269

270

271

272

273

274

Nine genes (nd2, atp8, atp6, cox3, nd5, $n d 4 l, n d 6, c o b, n d 1)$ share the same complete stop codon TAA, and four genes use incomplete stop codons (coxl, cox2 and nd4, nd3) (Table 3). Incomplete stop codons are common in lepidopteran mitogenomes and are presumed to be completed via post-transcriptional polyadenylation (Chen et al., 2016). Changes in stop codon usage among Dendrolimus were rarer than changes in start codon usage. Only in the cox 2 and nad2 genes, did we observe changes in the stop codon used. Therefore, we can conclude that even within congeneric species, start and stop codons are variable in the mitochondrial genome.

\section{(iv) Codon usage and RSCU}

Condon usage and relative synonymous codon usage (RSCU) results were compared across all available Dendrolimus mitogenomes (Supplemental Information 4). The analysis showed that Leu2 (UUR), Ile, Phe, Met, Asn, Gly, Ser2 (UCN), Tyr are the eight most frequent amino acids and were represented by at least 50 codons per thousand codons. Two codon families, Leu2 and Ile, had at least 100 codons per thousand codons. Leu2, a hydrophobic amino acid, was significantly more frequent than other amino acids, which may relate to the function of chondriosomes in many transmembrane proteins. The rarest used codon family was Cys.

The usage of both two-fold and four-fold degenerate codons was biased towards the use of codons with A or T in third position (Supplemental Information 5). Codons which have relatively high $\mathrm{G}$ and $\mathrm{C}$ content are likely to be abandoned, reflecting a finding across other lepidopteran insects. Examination of the fourteen individual Dendrolimus mitogenomes showed that Leu2 (UUA), Ser2 (UCU), Arg (CGA), Ala (GCU), Ser1 (AGA) are the five most frequent relative synonymous codons.

\section{(v) Non-coding regions, overlapping regions and $\mathrm{A}+\mathrm{T}$ rich region}

All fourteen mitogenomes had six overlapping regions and the size ranged from 1 to $8 \mathrm{bp}$ (Table 4). Nucleotide sequence of six mutual overlapping areas were almost identical, except for the overlap between $n d 2$ and $\operatorname{trn} W$ in $D$. kikuchii which was $1 \mathrm{bp}$ shorter than other species of Dendrolimus. In addition to the control region, there were 17 non-coding regions in the mitogenomes of D. punctatus, D. tabulaeformis and D. spectabilis, 18 in D. superans, 16 in D. 
275

276

277

278

279

280

281

282

283

284

285

286

287

288

289

290

291

292

293

294

295

296

297

298

299

300

301

kikuchii and 19 in D. houi (Table 4). It is noteworthy that there are 6 intergenic regions, trnQ-nad2 (54 bp - 58 bp), trnY-coxl (25 bp - 41 bp), atp6-cox3 (6 bp - 15 bp), trnA-trnR (9 bp - 20 bp), trnN$\operatorname{trnS}$ (AGN) (7 bp - $25 \mathrm{bp})$, nad4-nd4l (19 bp - 38bp), were longer than $15 \mathrm{bp}$. To investigate the utility, we constructed a phylogenetic tree of Dendrolimus species using only the A $+\mathrm{T}$ rich region and intergenic regions (Supplemental Information 5). The phylogenetic analysis using the A+T rich region produced similar but slightly different topology comparing with the whole mitogenomes.

\section{Sliding-window analysis}

Sliding-window analysis was conducted to compare nucleotide diversity among the mitochondrial protein-coding genes and non-coding regions of 14 individuals in Dendrolimus (Figure 4). The intergenic region has the highest nucleotide diversity which is likely attributable to the large indels in this region. This was followed by $n d 6, c y t b, \operatorname{cox} 2$, atp $6, \operatorname{cox} 3, n d 3, \mathrm{~A}+\mathrm{T}$ rich region, $n d 1, \operatorname{cox} 1$, $n d 2, n d 5, n d 4, n d 4 l, a t p 8$, rRNA, tRNA. It is notable that the nucleotide diversity of the A+T rich region was moderate; lower than many protein-coding genes. The tRNA was the most conserved region and cox 1 was the most conserved protein-coding gene. In contrast, sliding-window analyses using all 78 lepidopteran mitogenomes (same dataset as the phylogenetic analyses) produced substantially similar patterns: the $n d 6$ gene had the highest level of divergence and tRNA was the most conserved region, while the coxl was the most conserved than all protein-coding genes.

\section{Discussion}

The monophyly of each superfamily was generally well-supported based on the 78 mitogenome analysis, which was consistency with prior studies (Yang et al., 2009; Kawahara \& Breinholt., 2014; Qin et al., 2015). Previous studies have included Lasiocampidae within Bombycoidea (Brock, 1971; Scoble, 1992; Kawahara \& Breinholt., 2014), while other studies have treated Lasiocampidae as a distinct superfamily Lasiocampoidea (Minet, 1991; Regier et al., 2009; van Nieukerken et al., 2011; Zwick et al., 2011; Bazinet et al., 2013; Wu et al., 2016). However, according to our results based on mitogenomes, Lasiocampoidea and Bombycoidea were monophyletic and clustered together as sister groups with high support. Within the Bombycoidea, 
302 the relationship among the families Bombycidae, Sphingidae and Saturniidae has been difficult to 303 resolve in previous study (Regier et al., 2013). In our study, the analysis of both datasets placed 304 the Bombycidae as the sister group to Saturniidae and Sphingidae with high support (100\%

305

306

307

308

309

310

311

312

313

314

315

316

317

318

319

320

321

322

323

324

325

326

327

328 bootstrap), which is consistent with the phylogenetic relationship based on transcriptomic data (2696 genes) (Breinholt \& Kawahara, 2013).

The topology of our mitogenome Dendrolimus phylogeny showed some differences from the topology proposed by previous studies. Zhang et al. (2014) constructed a phylogeny of Dendrolimus based on one pheromone-binding proteins (PBP1) and two general odorant-binding proteins $(O B P S)$ in which D. kikuchii and D. houi was proposed as basal species of $D$. tabulaeformis, D. punctatus and D. spectabilis. The relationships of these three species were verified with mitogenomes analysis, sharing a closer relationship to each other with respect to $D$. superans. This result was also proved by the phylogenetic analysis of Dendrolimus based on COI and COII genes (Dai et al., 2012; Qin et al., 2015; Kononov et al., 2016). Two species, D. kikuchii and D. houi, were the most basal species in Dendrolimus. According to the phylogenetic tree based on whole mitogenomes, these two species could both be accept as monophyletic taxa, which was consistent with previous studies depended on COII and ITS genes (Dai et al., 2012; Kononov et $a l ., 2016)$. This result was different from the previous studies based on the analysis with $P B P 1$ and OBPs. The primary cause of this discrepancy is due to the different modes of inheritance, maternal for mtDNA and biparental for $P B P S, O B P S$ and ITS. Moreover, the dissimilarity in mutation rates and number of information sites could also lead to inconsistent results. For example, D. kikuchii and D. houi were the most closed related species based on the COI gene (Dai et al., 2012), however, paraphyletic groups were showed based on 5'-end portion of COI gene (Kononov et al., 2016). Not only that, the closed relationship of D. tabulaeformis, D. punctatus and D. spectabilis was also proved by the genetic distance analysis. D. superans was the sister species to these three species, which also had different mitogenome component characteristics.

The largest intergenic spacer of whole mitogenome is the A + T rich region, which not only has the characteristics of non-coding genes, but also contains important sites for the regulation of 
329

330

331

332

333

334

335

336

337

338

339

340

341

342

343

344

345

346

347

348

349

350

351

352

353

354

355

transcription and replication (Gissi et al., 2008), as well as useful phylogenetic signals, particularly for determining congeneric relationships and relationships among recently diverged species. The results of phylogenetic analysis using the $\mathrm{A}+\mathrm{T}$ rich region produced similar but slightly different topology comparing with the whole mitogenomes, which This suggests the intergenic regions might be too variable to be useful for phylogenetic analyses, nevertheless, the $\mathrm{A}+\mathrm{T}$ rich region might be an effective molecular tool in solving phylogenetic relationships among recently diverged species.

\section{Conclusion}

In this study, both phylogenetic and genetic distance analyses obtained consistent results regarding the relationships among six closely related species. The whole mitogenomes failed to provide enough information to distinguish D. tabulaeformis from D. punctatus, which suggest there might not be a clear species boundary between these two species. This finding is consistent with the results of previous studies, in which $D$. tabulaeformis was regarded as ecological type of $D$. punctatus based on several DNA markers and experiments of interspecific hybridization. Meanwhile, D. spectabilis fell as sister to these two sibling species, and D. superans fell as sister to these three taxa. D. kikuchii and D. houi are sister species, having relatively close relationship comparing with other four species. The phylogenetic relationships of Dendrolimus based on complete mitogenome could provide a theoretical basis for pest control of pine caterpillar, thereby reducing the economic losses of forests.

Congeneric species exhibit similar mitochondrial genome features, such as genome organization, nucleotide composition, codon usage and RSCU. Within the genus Dendrolimus, start and stop codons were variable in mitochondrial genome and the change of stop codons were rarer than start codons. Non-coding regions were the most variable regions in mitochondrial genomes. When comparing nucleotide diversity, the nad6 gene had the highest level of divergence and the tRNA region was the most conserved.

\section{Acknowledgements}


356 The authors wish to thank Prof. Xiang-Bo Kong (Chinese Academy of Forestry) for helping with 357 sample collection.

358

359

360

361

362

363

364

365

366

367

368

369

370

371

372

373

374

\section{Reference:}

1. Baranchikov Y, Pet'ko V, Ponomarev V. 2006. The Russians are coming - aren't they? Siberian moth in European forests. In: Gottschalk K, Fosbroke S, editors. Proceedings, Interag. Res. forum gypsy moth other invasive species. Washington: USDA Forest Service. p. $18-20$.

2. Bazinet AL, Cummings MP, Mitter KT, Mitter CW. 2013. Can RNA-Seq resolve the rapid radiation of advanced moths and butterflies (Hexapoda: Lepidoptera: Apoditrysia)? An exploratory study. PLOS ONE 8: e82615. DOI 10.1371/journal.pone.0082615

3. Bergsten J. 2005. A review of long-branch attraction. Cladistics 21(2): 163-193. DOI10.1111/j.1096-0031.2005.00059.x

4. Boore JL. 1999. Animal mitochondrial genomes. Nucleic Acids Research 27: 1767-80. DOI $\underline{10.1093 / \mathrm{nar} / 27.8 .1767}$

5. Boore JL. 2006. The use of genome-level characters for phylogenetic reconstruction. Trends in Ecology and Evolution 21: 439-46. DOI 10.1016/j.tree.2006.05.009

6. Brock J. 1971. A contribution towards an understanding of the morphology and phylogeny of the Ditrysian Lepidoptera. Journal of Natural History 5: 29-102. DOI $\underline{10.1080 / 00222937100770031}$

7. Cameron SL, Lambkin CL, Barker SC, Whiting MF. 2007. A mitochondrial genome phylogeny of Diptera: whole genome sequence data accurately resolve relationships over broad timescales with high precision. Systematic Entomology 32: 40-59. DOI 10.1111/j.13653113.2006.00355.x

8. Chen C, Qiang Y, Peng XY, Qian ZQ, Wang ZZ. 2016. The complete mitochondrial genome of the Sara Longwing Heliconius sara (Insecta: Lepidoptera: Nymphalidae). Mitochondrial 
DNA Part A 27: 3167-3168.

384

385

386

387

388

389

390

391

392

393

394

395

396

397

398

399

400

401

402

403

404

405

406

407

408

409

9. Chen CJ. 1990. In Integrated Management of Pine Caterpillar in China. Beijing, China: China Forestry Press. (in Chinese)

10. Curole JP, Kocher TD. 1999. Mitogenomics: digging deeper with complete mitochondrial genomes. Trends in Ecology and Evolution 14: 394-8. DOI 10.1016/S0169-5347(99)01660$\underline{2}$

11. Dai QY, Gao Q, Wu CS, Chesters D, Zhu CD, Zhang AB. 2012. Phylogenetic reconstruction and DNA barcoding for closely related pine moth species (Dendrolimus) in China with multiple gene markers. PLOS ONE 7: e32544. DOI 10.1371/journal.pone.0032544

12. Diaz JH. 2005. The evolving global epidemiology, syndromic classification, management, and prevention of caterpillar envenoming. The American journal of tropical medicine and hygien 72:347-357.

13. Edgar RC. 2004. MUSCLE: multiple sequence alignment with high accuracy and high throughput. Nucleic Acids Research 32(5): 1792-1797. DOI 10.1093/nar/gkh340.

14. Gissi C, Iannelli F, Pesole G. 2008. Evolution of the mitochondrial genome of Metazoa as exemplified by comparison of congeneric species. Heredity 101: 301-20.

15. Guéguen L, Gaillard S, Boussau B, Gouy M, Groussin M, Rochette NC, Bigot T, Fournier D, Pouyet F, Cahais V, Bernard A, Scornavacca C, Nabholz B, Haudry A, Dachary L, Galtier N, Belkhir K, Dutheil JY. 2013. Bio++: efficient extensible libraries and tools for computational molecular evolution. Molecular Biology and Evolution 30: 1745-50. DOI $\underline{10.1093 / \mathrm{molbev} / \mathrm{mst} 097}$

16. Hebert PD, Cywinska A, Ball SL. 2003. Biological identifications through DNA barcodes. Proceedings of the Royal Society of London B: Biological Sciences 270: 313-21. DOI $\underline{10.1098 / \mathrm{rspb} .2002 .2218}$

17. Hou T. 1987. The Pine Caterpillars in China., Beijing, China:Science Press. (in Chinese)

18. Kawahara AY, Breinholt JW. 2014. Phylogenomics provides strong evidence for relationships of butterflies and moths. Proceeding of the Royal Society B: Biological Sciences 
410

411

412

413

414

415

416

417

418

419

420

421

422

423

424

425

426

427

428

429

430

431

432

433

434

435

436

281:20140970. DOI 10.1098/rspb.2014.0970

19. Kononov A, Ustyantsev K, Wang B-D,. Mastro VC, FetmV, Blinov A, Baranchikov Y. 2016. Genetic diversity among eight Dendrolimus species in Eurasia (Lepidoptera: Lasiocampidae) inferred from mitochondrial COI and COII, and nuclear ITS2 markers. BMC genetics 17 (suppl 3):157.

20. Lanfear R, Calcott B, Ho SY, Guindon S. 2012. PartitionFinder: combined selection of partitioning schemes and substitution models for phylogenetic analyses. Molecular Biology and Evolution 29: 1695-701.56. DOI 10.1093/molbev/mss020

21. Librado P, Rozas J. 2009. DnaSP v5: a software for comprehensive analysis of DNA polymorphism data. Bioinformatics 25: 1451-2. DOI 10.1093/bioinformatics/btp187

22. Liu YQ, Wu CS. 2006. Fauna sinica: insecta (vol 47) (Lepidoptera: Lasiocampidae). Beijing Science Press, Beijing, pp 336-339.

23. Masta SE, Boore JL. 2008. Parallel evolution of truncated transfer RNA genes in arachnid mitochondrial genomes. Molecular Biology and Evolution 25: 949-59. DOI 10.1093/molbev/msn051

24. Mikkola K, Ståhls G. 2008. Morphological and molecular taxonomy of Dendrolimus sibiricus Chetverikov stat. rev. and allied lappet moths (Lepidoptera: Lasiocampidae), with description of a new species. Entomologica Fennica 8(19):65-85.

25. Minet J. 1991. Tentative reconstruction of the ditrysian phylogeny (Lepidoptera: Glossata). Insect Systematics and Evolution 22 (1): 69-95.

26. van Nieukerken EJ, Kaila L, Kitching IJ, Kristensen NP, Lees D, Minet J. 2011. Order Lepidoptera Linnaeus, 1758. Zootaxa 3148: 212-21.

27. Perna NT, Kocher TD. 1995. Patterns of nucleotide composition at fourfold degenerate sites of animal mitochondrial genomes. Journal of Molecular Evolution 41: 353-8. DOI $\underline{10.1007 / \mathrm{BF} 00186547}$

28. Posada D, Buckley TR. 2004. Model selection and model averaging in phylogenetics: advantages of Akaike information criterion and Bayesian approaches over likelihood ratio 
437

438

439

440

441

442

443

444

445

446

447

448

449

450

451

452

453

454

455

456

457

458

459

460

461

462

463

tests. Systematic Biology 53: 793-808. DOI 10.1080/10635150490522304

29. Qin J, Zhang Y, Zhou X, Kong X, Wei S, Ward RD, Zhang AB. 2015. Mitochondrial phylogenomics and genetic relationships of closely related pine moth (Lasiocampidae: Dendrolimus) species in China, using whole mitochondrial genomes. BMC Genomics 16: 1. DOI 10.1186/s12864-015-1566-5

30. Rambaut A, Drummond A. 2007. http://beast. bio. ed. ac. uk/Tracer. Tracer v1. 4.

31. Ramírez-Ríos V, Franco-Sierra ND, Alvarez JC, Saldamando-Benjumea CI, Villanueva-Mejía DF. 2016. Mitochondrial genome characterization of Tecia solanivora (Lepidoptera: Gelechiidae) and its phylogenetic relationship with other lepidopteran insects. Gene 581:107116.

32. Regier JC, Zwick A, Cummings MP, Kawahara AY, Cho S, Weller S, Roe A, Baixeras J, Brown JW, Parr C, Davis DR, Epstein M, Hallwachs W, Hausmann. A, Janzen DH, Kitching IJ, Solis MA, Yen SH, Bazinet AL, Mitter C. 2009. Toward reconstructing the evolution of advanced moths and butterflies (Lepidoptera: Ditrysia): an initial molecular study. $B M C$ Evolutionary Biology 9: 280. DOI 10.1186/1471-2148-9-280

33. Regier JC, Mitter C, Zwick A, Bazinet AL, Cummings MP, Kawahara AY, Sohn JC, Zwick1 DJ, Cho S, Davis DR, Baixeras J, Brown J, Parr C, Weller S, Lees DC, Mitter KT. 2013. A large-scale, higher-level, molecular phylogenetic study of the insect order Lepidoptera (moths and butterflies). PLOS ONE 8: e58568. DOI 10.1371/journal.pone.0058568

34. Ronquist F, Huelsenbeck JP. 2003. MrBayes 3: Bayesian phylogenetic inference under mixed models. Bioinformatics 19: 1572-4. DOI 10.1093/bioinformatics/btg180

35. Ronquist F, Teslenko M, van der Mark P, Ayres DL, Darling A, Höhna S, Larget B, Liu L, Suchard MA, Huelsenbeck JP. 2012. MrBayes 3.2: efficient Bayesian phylogenetic inference and model choice across a large model space. Systematic Biology 61: 539-42. DOI 10.1093/sysbio/sys029

36. Salvato P, Simonato M, Battisti A, Negrisolo E. 2008. The complete mitochondrial genome of the bag-shelter moth Ochrogaster lunifer (Lepidoptera, Notodontidae). BMC Genomics 9: 


\section{DOI 10.1186/1471-2164-9-331}

37. Scoble MJ. 1992. The Lepidoptera. Form, function and diversity: Oxford University Press.

38. Simon C, Frati F, Beckenbach A, Crespi B, Liu H, Flook P. 1994. Evolution, weighting, and phylogenetic utility of mitochondrial gene sequences and a compilation of conserved polymerase chain reaction primers. Annals of the Entomological Society Of America 87: 651701. DOI 10.1093/aesa/87.6.651

39. Simon C, Buckley TR, Frati F, Stewart JB, Beckenbach AT. 2006. Incorporating molecular evolution into phylogenetic analysis, and a new compilation of conserved polymerase chain reaction primers for animal mitochondrial DNA. Annual Review of Ecology, Evolution, and Systematics 37: 1 545-79. DOI 10.1146/annurev.ecolsys.37.091305.110018

40. Stamatakis A. 2006. RAxML-VI-HPC: maximum likelihood-based phylogenetic analyses with thousands of taxa and mixed models. Bioinformatics 22: 2688-90. DOI $\underline{10.1093 / \text { bioinformatics/btl446 }}$

41. Tamura K. 2011. MEGA5: molecular evolutionary genetics analysis using maximum likelihood, evolutionary distance, and maximum parsimony methods. Molecular Biology and Evolution 28: 2731-9. DOI 10.1093/molbev/msr121

42. Timmermans MJ, Lees DC, Simonsen TJ. 2014. Towards a mitogenomic phylogeny of Lepidoptera. Molecular Phylogenetics and Evolution 79: 169-78. DOI 10.1016/j.ympev.2014.05.031

43. Tsai P, Liu Y. 1962. A study of the genus Dendrolimus (Lasiocampidae) of China with descriptions of two new species and one new subspecies. Acta Entomol Sin 11: 237-52.

44. Vaidya G, Lohman DJ, Meier R. 2011. SequenceMatrix: concatenation software for the fast assembly of multi-gene datasets with character set and codon information. Cladistics 27: 17180. DOI 10.1111/j.1096-0031.2010.00329.x

45. Wei T. 2013. corrplot: Visualization of a correlation matrix. R package version 073.

46. Whiting MF, Carpenter JC, Wheeler QD, Wheeler WC. 1997. The Strepsiptera problem: phylogeny of the holometabolous insect orders inferred from $18 \mathrm{~S}$ and $28 \mathrm{~S}$ ribosomal DNA 
491

492

493

494

495

496

497

498

499

500

501

502

503

504

505

506

507

508

509

510

511

512

513

514

515

516

517

sequences and morphology. Systematic Biology 46: 1-68. DOI 10.1093/sysbio/46.1.1

47. Wilson K, Cahill V, Ballment E, Benzie J. 2000. The complete sequence of the mitochondrial genome of the crustacean Penaeus monodon: are malacostracan crustaceans more closely related to insects than to branchiopods? Molecular Biology and Evolution 17: 863-874. DOI $\underline{10.1093 / o x f o r d j o u r n a l s . m o l b e v . a 026366 ~}$

48. Wu LY, Xiong X, Wang XM, Xin TR, Wang J, Zou ZW, Xia B. 2016. The complete mitochondrial genome of Trabala vishnou guttata (Lepidoptera: Lasiocampidae) and the related phylogenetic analyses. Genetica 144:675-688. DOI 10.1007/s10709-016-9934X

49. Xia X, Xie Z. 2001. DAMBE: Software Package for Data Analysis in Molecular Biology and Evolution. Journal of Heredity 92(4): 371-373. DOI:10.1093/jhered/92.4.371.

50. Yang L, Wei ZJ, Hong GY, Jiang ST, Wen LP. 2009. The complete nucleotide sequence of the mitochondrial genome of Phthonandria atrilineata (Lepidoptera: Geometridae). Molecular Biology Reports 36: 1441-9. DOI 10.1007/s11033-008-9334-0

51. Yang X, Cameron SL, Lees DC, Xue D, Han H. 2015. A mitochondrial genome phylogeny of owlet moths (Lepidoptera: Noctuoidea), and examination of the utility of mitochondrial genomes for lepidopteran phylogenetics. Molecular Phylogenetics and Evolution 85: 230-7. DOI 10.1016/j.ympev.2015.02.005

52. Zardoya R, Meyer A. 1996. Phylogenetic performance of mitochondrial protein-coding genes in resolving relationships among vertebrates. Molecular Biology and Evolution 13: 933-42. DOI 10.1093/oxfordjournals.molbev.a025661

53. Zhang A, Kong X, Li D, Liu Y. 2003. DNA fingerprinting evidence for the phylogenetic relationship of eight species and subspecies of Dendrolimus (Lepidoptera: Lasiocampidae) in China. Acta entomologica Sinica 47: 236-42.

54. Zhang A, Zhang Z, Wang H, Kong X. 2003. Geographical distribution of Lasiocampidae in China and its relationship with environmental factors. Journal of Beijing Forestry University. 26: 54-60. 
518 55. Zhang SF, Zhang Z, Kong XB, Wang HB. 2014. Molecular characterization and phylogenetic 519 analysis of three odorant binding protein gene transcripts in Dendrolimus species 520 (Lepidoptera: Lasiocampidae). Insect science 21: 597-608. DOI 10.1111/1744-7917.12074

521 56. Zhao QS, Wu WB, Lu GP, Yuan X, Li SK, Jiang JC. 1992. Hybridization experiments with 522 two species of Dendrolimus. Acta Entomologica Sinica 35:29-32.

523 57. Zwick A, Regier JC, Mitter C, Cummings MP. 2011. Increased gene sampling yields robust 524 support for higher-level clades within Bombycoidea (Lepidoptera). Systematic Entomology 525 36(1):31-43. doi:10.1111/j.1365-3113.2010.00543.x 


\section{Figure 1}

Phylogenetic relationship of Dendrolimus.

Figure 1: (A) Cladogram (ML and BI) depicting six Dendrolimus species constructed with Maximum Likelihood and Bayesian inference analyses of (i) 13 protein coding genes (13PCGs); (ii) 37 genes (13 protein-coding genes+22 transfer RNA genes+2 ribosomal RNA genes, 37gene). Numbers above or below branches indicate posterior probabilities and bootstrap percentages across the difference analyses and datasets (13PCGs-BI / 13PCGs-ML / 37gene-BI / 37gene-ML). (B) Cladogram constructed using Bayesian inference analysis of nucleotide sequences of 13 mitochondrial protein-coding genes of Lepidopteran (moth) species, plus outgroups. Numbers above or below branches indicate posterior probabilities. 
A)

B)
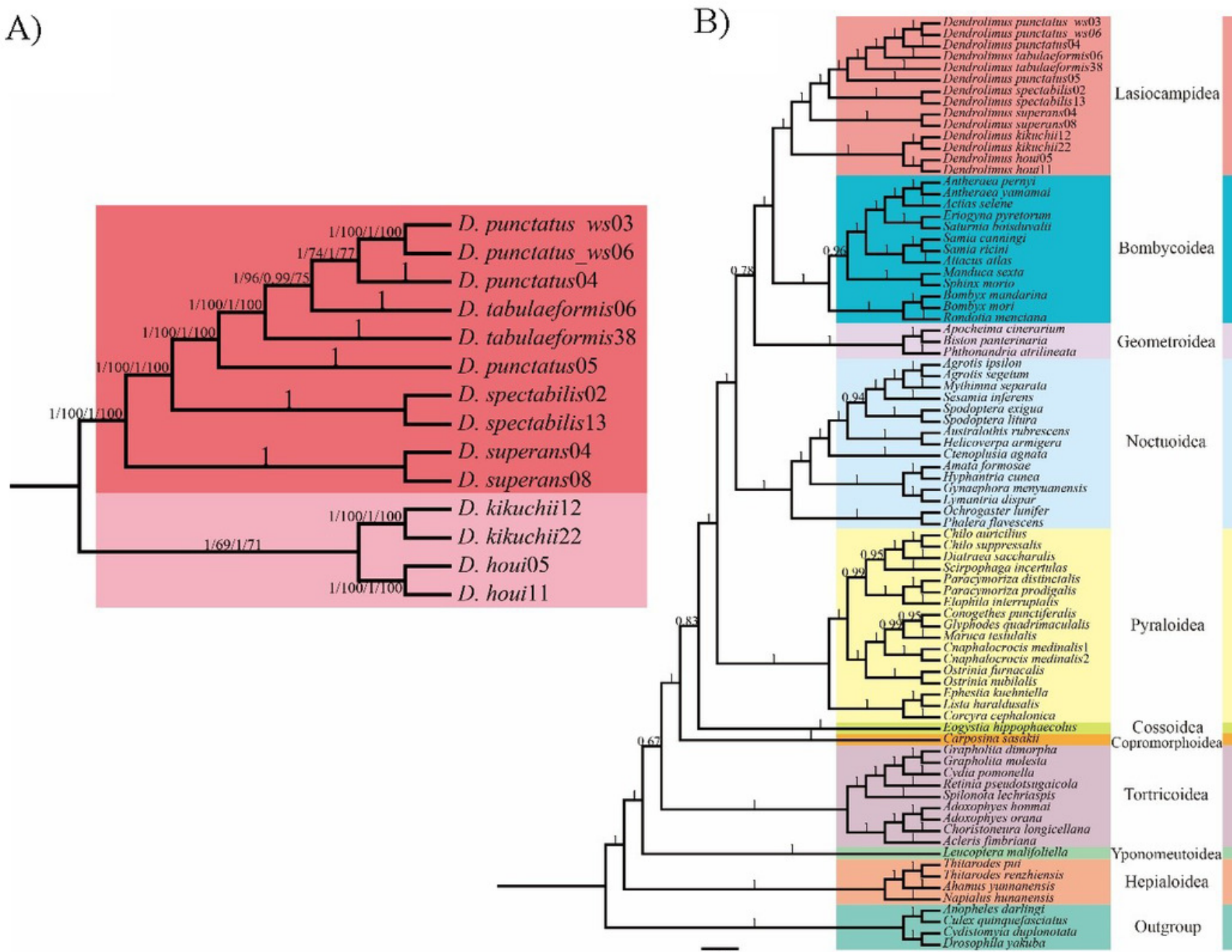


\section{Figure 2}

Phylogeny of Lasiocampoidea.

Figure 2. (A)Phylogenetic tree ( $M L$ and $B \mathrm{~B}$ ) of Bombycoidea + Lasiocampoidea species with outgroups(Geoetroidea) constructed with (1)13 protein coding genes(13PCGs); (2)37 genes (13 protein-coding genes +22 transfer RNA genes +2 ribosomal RNA genes,ootstrap, 37genes) Numbers above branches indicate bootstrap values, in the order of presentation 13PCGs-ML/13 PCGs-BI/37gene-ML/37gene-BI. Clades with different colors indicate different superfamilies. (B)Phylogeny of Dendrolims based on 13 protein coding genes (13PCGs). Only $\mathrm{COI}$ and COIl sequences of $D$. sibircus were used. Numbers above or below branches indicate bootstrap values, in the order of presentation 13PCGs-ML/13PCGs-BI. 
A)

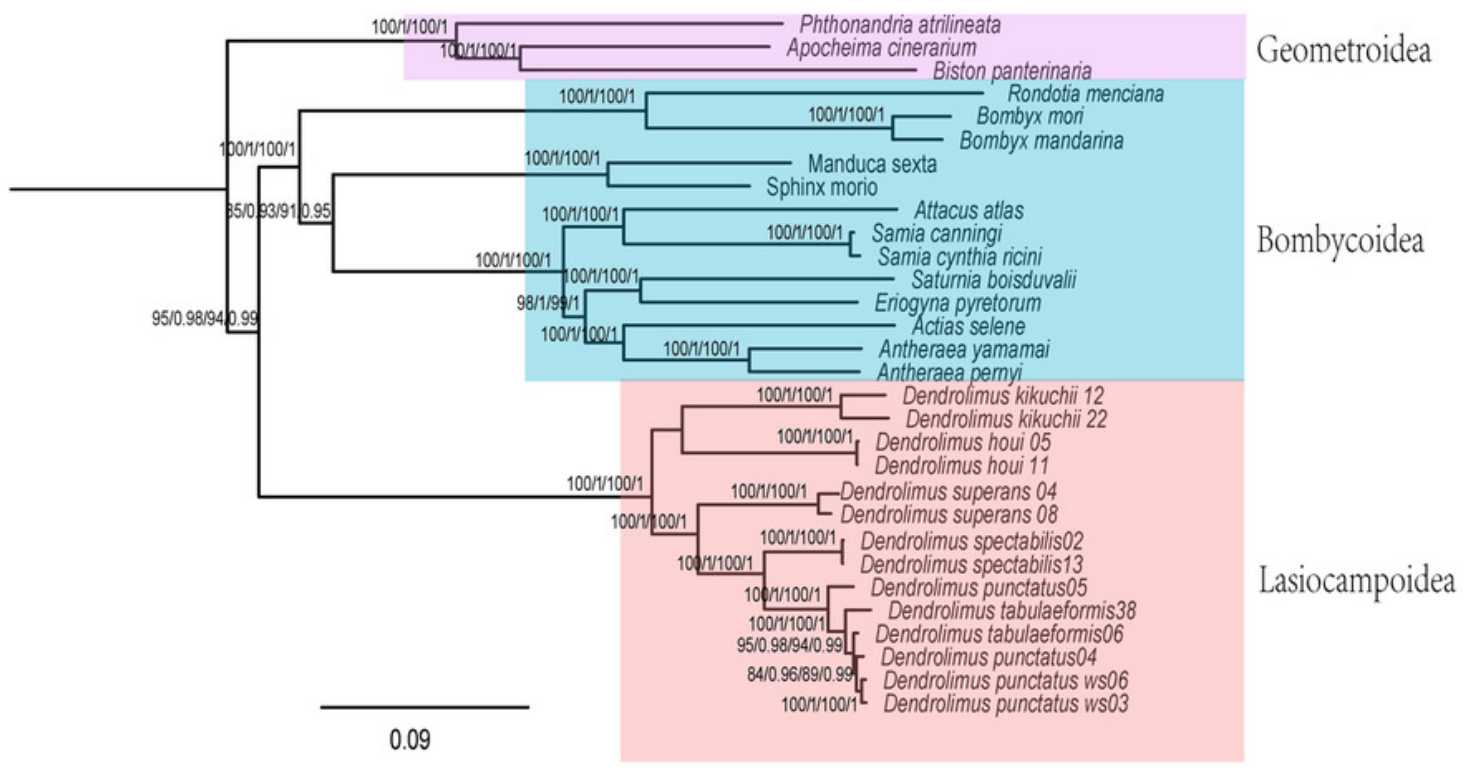

B)

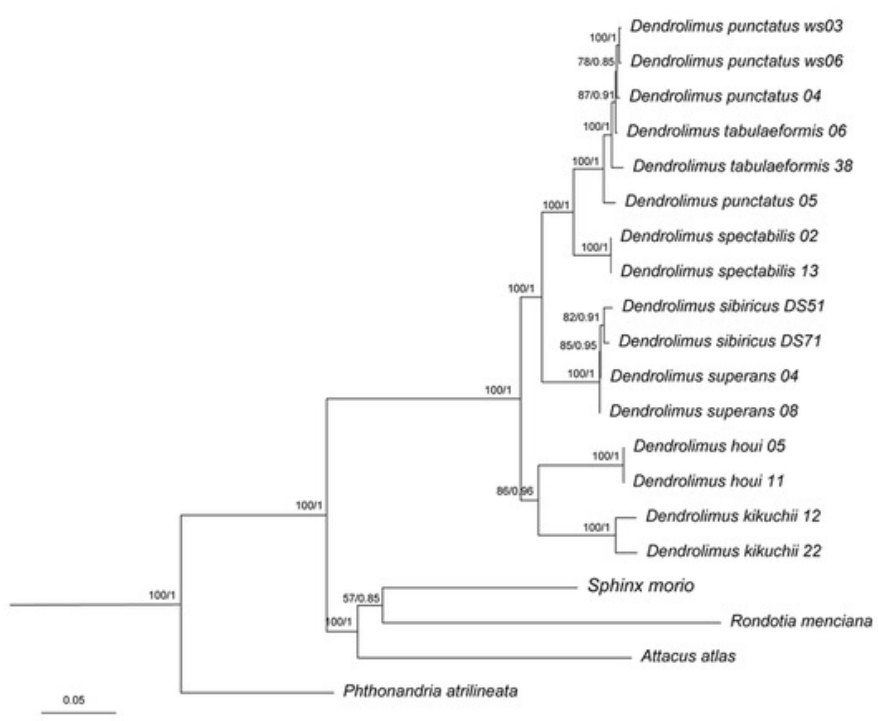


Figure 3

Genetic distance of six Dendrolimus species

Figure 3 Genetic distance (below diagonal) and correlation relationship (above diagonal) of (A)13 concatenate protein coding genes and (B) 37 concatenate genes. The size of circle stands for the correlation values, which range from -1 to 1 . Values closer to 1 indicate a closer relationship. Species names were abbreviated: D. spectabilis (CS02 and CS13), D. tabulaeformis (YS06 and YS08), D. punctatus punctatus (MW04 and MW05), D. punctatus wenshanensis (WS03 and WS06), D. superans (LY04 and LY08), D. kikuchii (SM12 and SM22), D. houi (YN05 and YN11).

A)

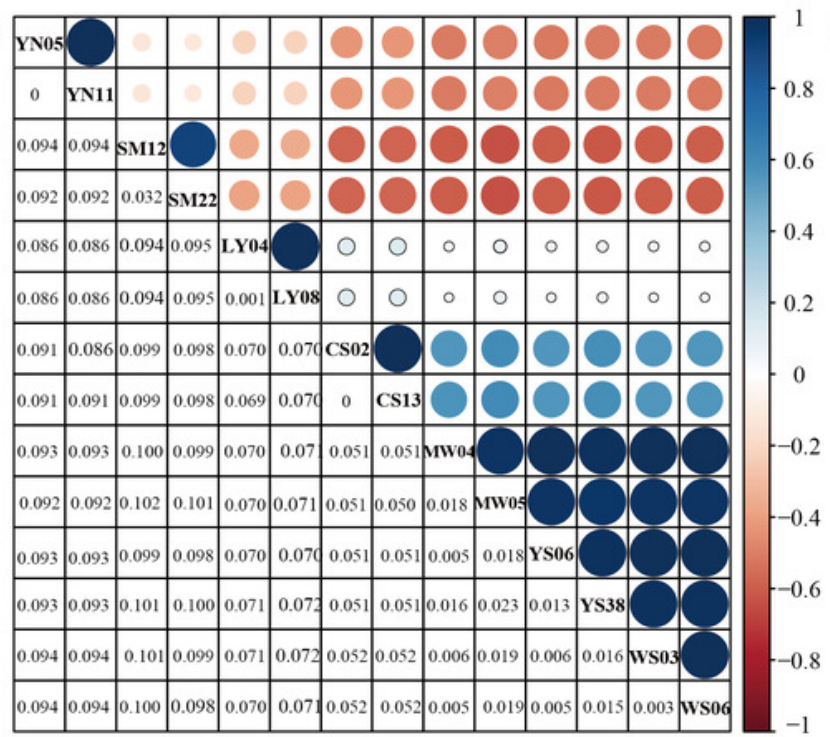

B)

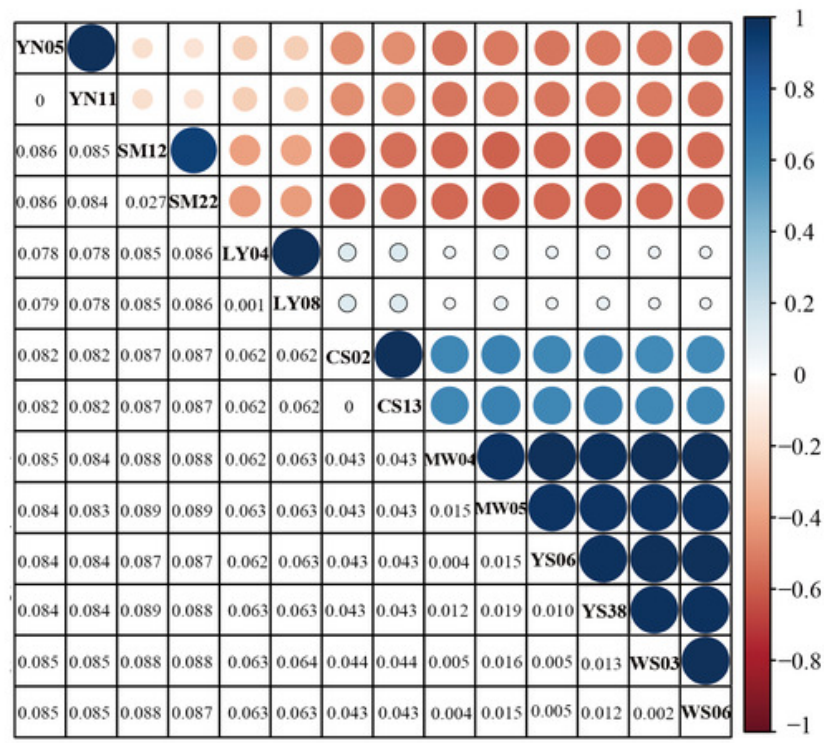




\section{Figure 4}

Sliding-window analyses of 13 protein coding genes among six Dendrolimus species.

Figure 4. Sliding-window analyses of 13 protein coding genes, concatenated tRNA and rRNA genes, intergenic and $\mathrm{A}+\mathrm{T}$ rich region among six Dendrolimus species. The $\mathrm{X}$-axis represents sequence length, the $Y$-axis represents nucleotide diversity. The red dotted line indicates the average nucleotide diversity. 

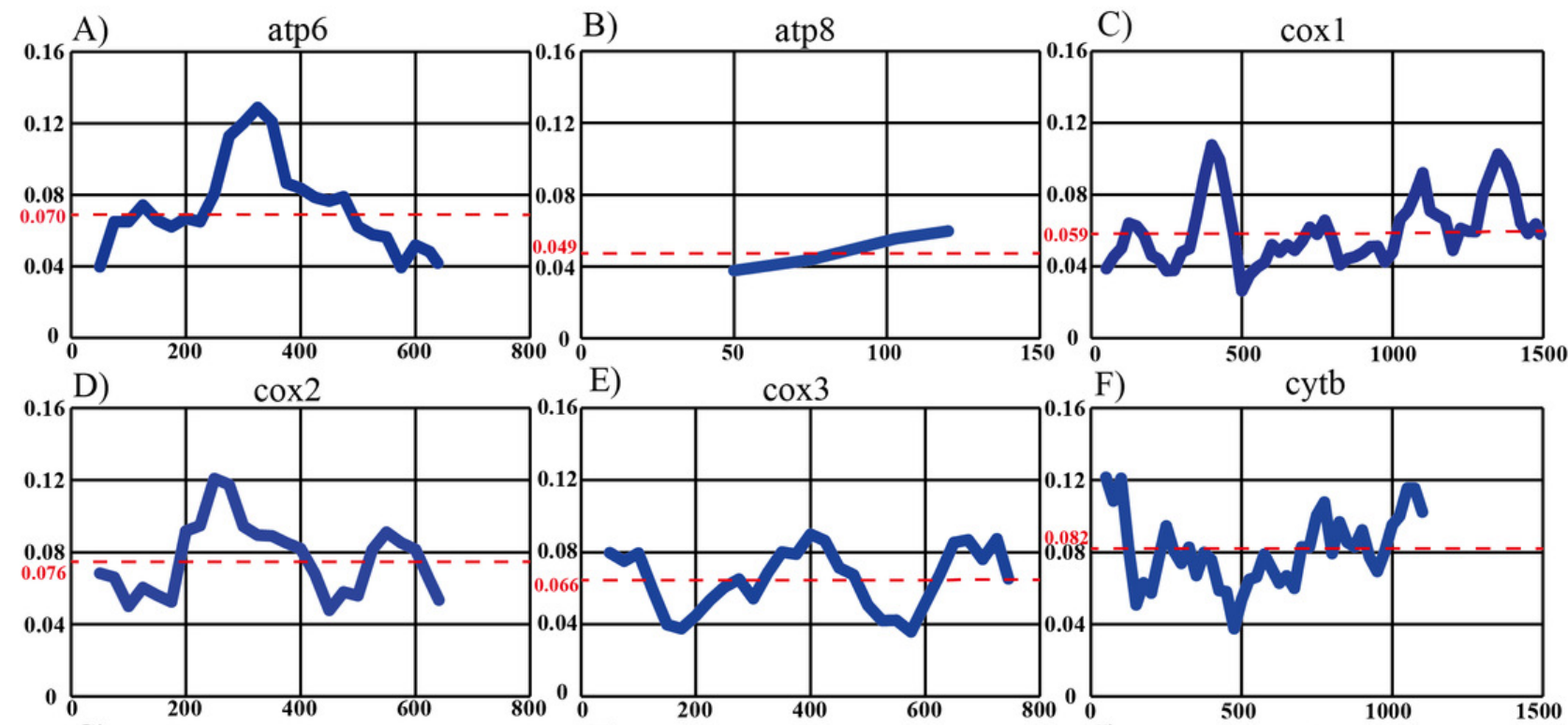

E) $\quad \operatorname{cox} 3$

F) cytb
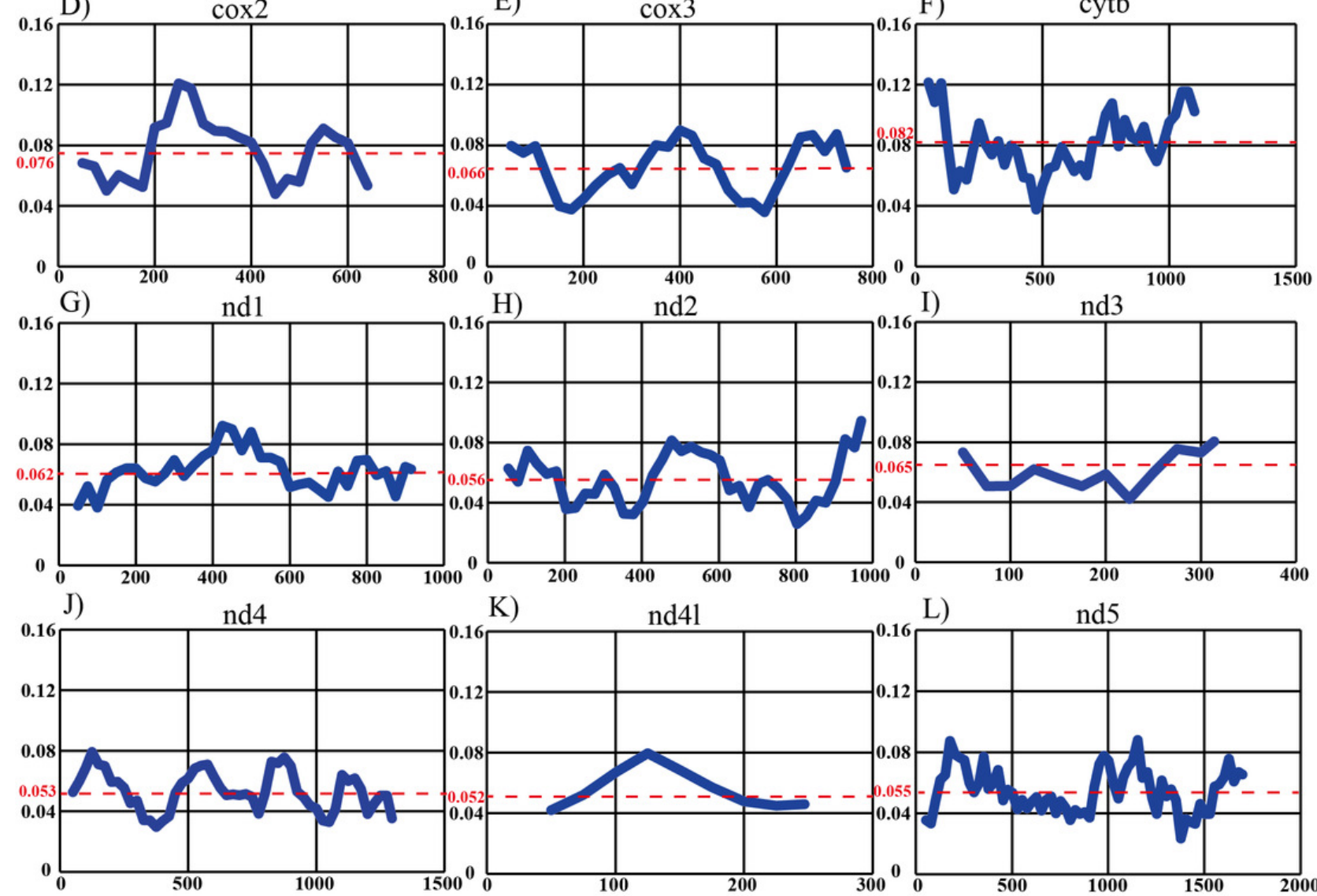

K)

L)

nd5
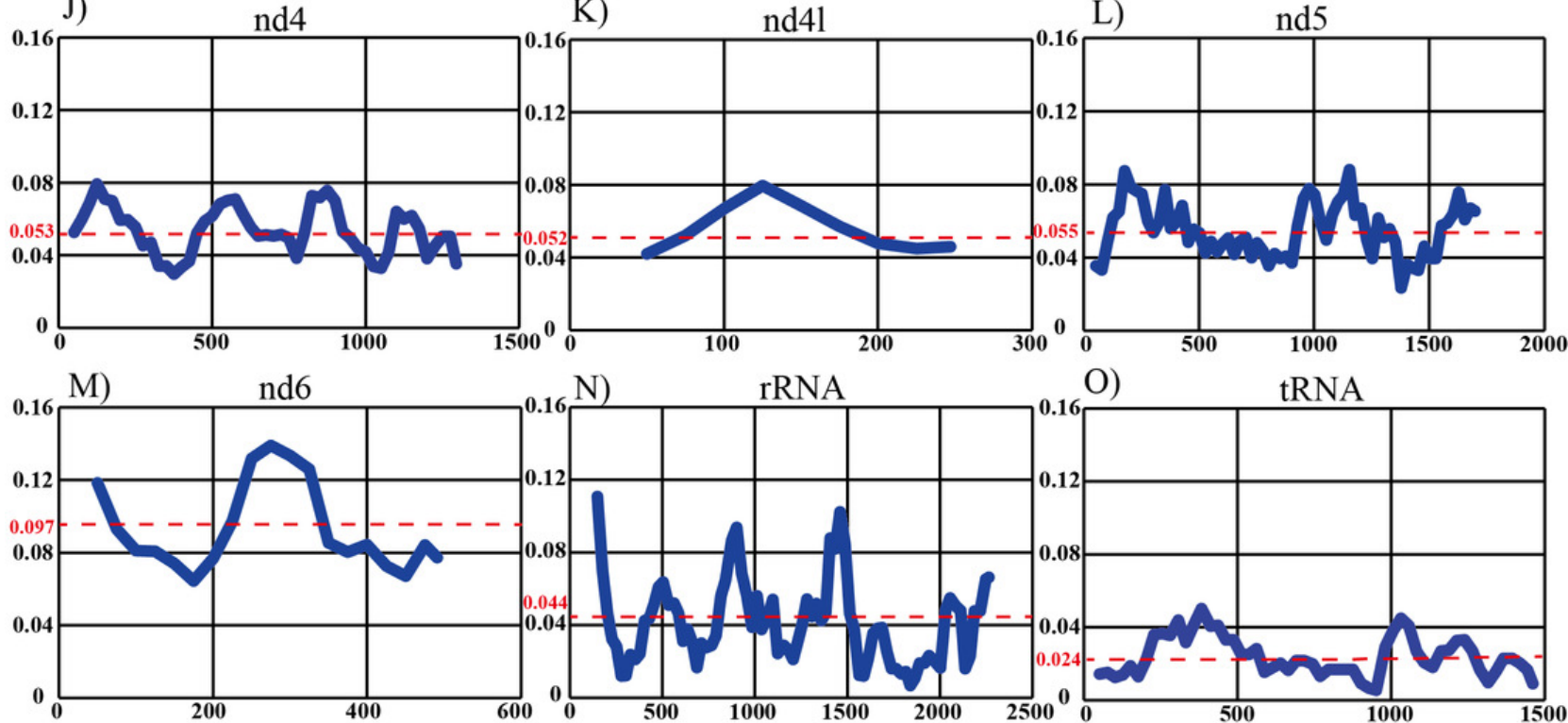

O)

tRNA
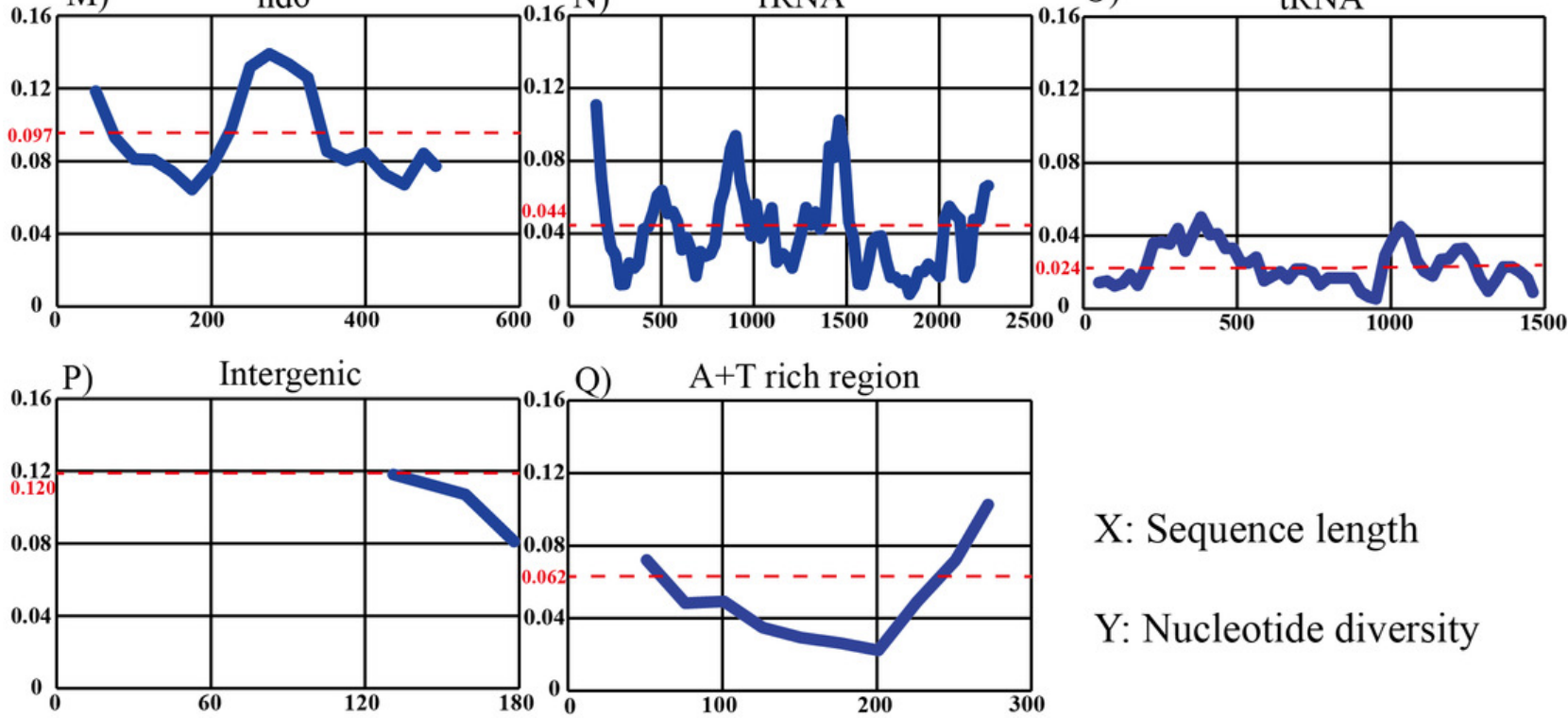

$\mathrm{X}$ : Sequence length

Y: Nucleotide diversity

PeerJ reviewing PDF | (2019:02:35083:1:1:NEW 31 May 2019) 


\section{Table $\mathbf{1}$ (on next page)}

Sample localities in China, geographical coordinates and altitude of Dendrolimus superans, D. kikuchii and D. houi.

Table 1. Sample localities in China, geographical coordinates and altitude of Dendrolimus superans, D. kikuchii and D. houi. 
Table 1 Sample localities in China, geographical coordinates and altitude of Dendrolimus superans, D. kikuchii and D. houi.

\begin{tabular}{|c|c|c|c|c|}
\hline Specimen (code) & Sample locality & Latitude $\left({ }^{\circ} \mathrm{N}\right)$ & Longitude $\left({ }^{\circ} \mathbf{E}\right)$ & Altitude(m) \\
\hline \multirow[t]{2}{*}{ D. superans04 (LY04) } & Keshenketengqi, & 43.15 & 117.32 & 1198 \\
\hline & Inner Mongolia & & & \\
\hline \multirow[t]{2}{*}{ D. superans08 (LY08) } & Keshenketengqi, & 43.15 & 117.32 & 1198 \\
\hline & Inner Mongolia & & & \\
\hline D. kikuchii12 (SM12) & Shilin, Yunnan & 24.45 & 103.16 & 1888 \\
\hline D. kikuchii22 (SM22) & Zhenyuan, Guizhou & 23.43 & 101.08 & 1057 \\
\hline D. houi05 (YN05) & Zhenyuan, Guizhou & 23.43 & 101.08 & 1057 \\
\hline D. houi11 (YN11) & Jingdong, Yunnan & 24.27 & 100.05 & 1444 \\
\hline
\end{tabular}

1 


\section{Table 2 (on next page)}

Genome organization of $D$. kikuchii, D. houi and D. superans.

Table 2. Genome organization of D. kikuchii (sample ID: SM12 and SM22), D. houi ( sample ID: YN05 and YN11) and D. superans ( sample ID: LY04 and LY08). 
1 Table 2. Genome organization of D. kikuchii (SM12 and SM22), D. houi (YN05 and YN11) and D. superans (LY04 2 and LY08).

\begin{tabular}{|c|c|c|c|c|c|c|c|}
\hline \multirow{2}{*}{ Gene } & \multirow{2}{*}{ Strand } & \multicolumn{6}{|c|}{ Location } \\
\hline & & SM12 & SM22 & YN05 & YN11 & LY04 & LY08 \\
\hline $\operatorname{trnM}$ & $\mathrm{F}$ & $1-67$ & $1-67$ & $1-67$ & $1-67$ & $1-68$ & $1-67$ \\
\hline $\operatorname{trnI}$ & $\mathrm{F}$ & 71-134 & 71-134 & $69-132$ & $69-132$ & $72-135$ & $72-135$ \\
\hline $\operatorname{trnQ}$ & $\mathrm{R}$ & $132-200$ & $132-200$ & $130-198$ & $130-198$ & $133-201$ & 133-201 \\
\hline $\operatorname{nad} 2$ & $\mathrm{~F}$ & $257-1264$ & $255-1262$ & 254-1264 & $254-1264$ & $256-1266$ & $256-1266$ \\
\hline $\operatorname{trnW}$ & $\mathrm{F}$ & $1264-1334$ & $1262-1332$ & $1263-1332$ & $1263-1332$ & $1265-1336$ & $1265-1335$ \\
\hline $\operatorname{trnC}$ & $\mathrm{R}$ & $1327-1392$ & $1325-1390$ & $1325-1391$ & $1325-1391$ & 1329-1394 & $1328-1393$ \\
\hline $\operatorname{trn} Y$ & $\mathrm{R}$ & $1393-1460$ & 1391-1458 & $1393-1463$ & $1393-1463$ & $1395-1460$ & 1394-1459 \\
\hline $\operatorname{cox} 1$ & $\mathrm{~F}$ & $1501-3031$ & $1500-3030$ & $1492-3022$ & $1492-3022$ & $1493-3023$ & $1492-3022$ \\
\hline $\operatorname{trnL}(\mathrm{UUR})$ & $\mathrm{F}$ & $3032-3098$ & $3031-3097$ & 3023-3089 & 3023-3089 & $3024-3090$ & 3023-3089 \\
\hline $\operatorname{cox} 2$ & $\mathrm{~F}$ & $3099-3780$ & $3098-3779$ & $3090-3773$ & $3090-3773$ & $3091-3772$ & $3090-3771$ \\
\hline $\operatorname{trn} K$ & $\mathrm{~F}$ & $3781-3851$ & $3780-3850$ & $3775-3845$ & $3775-3845$ & $3773-3843$ & $3772-3842$ \\
\hline $\operatorname{trnD}$ & $\mathrm{F}$ & $3852-3919$ & $3851-3918$ & $3847-3913$ & $3847-3913$ & $3847-3914$ & $3846-3913$ \\
\hline atp8 & $\mathrm{F}$ & $3920-4081$ & $3919-4080$ & $3914-4075$ & $3914-4075$ & $3915-4076$ & $3914-4075$ \\
\hline atp6 & $\mathrm{F}$ & $4075-4752$ & $4074-4751$ & $4069-4746$ & $4069-4746$ & $4070-4747$ & $4069-4746$ \\
\hline $\operatorname{cox} 3$ & $\mathrm{~F}$ & $4759-5547$ & $4760-5548$ & $4762-5550$ & $4762-5550$ & $4760-5548$ & $4759-5547$ \\
\hline $\operatorname{trnG}$ & $\mathrm{F}$ & $5550-5616$ & $5551-5617$ & $5553-5618$ & $5553-5618$ & $5551-5616$ & $5550-5615$ \\
\hline nad3 & $\mathrm{F}$ & $5617-5970$ & $5618-5971$ & $5619-5970$ & $5619-5970$ & $5617-5970$ & 5616-5969 \\
\hline $\operatorname{trn} A$ & $\mathrm{~F}$ & 5973-6039 & $5974-6039$ & $5971-6038$ & $5971-6038$ & $5975-6041$ & $5974-6040$ \\
\hline $\operatorname{trnR}$ & $\mathrm{F}$ & $6058-6123$ & $6058-6123$ & $6048-6112$ & $6048-6112$ & $6055-6118$ & $6054-6117$ \\
\hline $\operatorname{trnN}$ & $\mathrm{F}$ & $6145-6211$ & $6145-6211$ & 6118-6184 & 6118-6184 & $6120-6185$ & 6119-6184 \\
\hline $\operatorname{trnS}(\mathrm{AGN})$ & $\mathrm{F}$ & $6226-6293$ & $6219-6286$ & $6210-6277$ & $6210-6277$ & $6202-6269$ & $6201-6268$ \\
\hline $\operatorname{trn} E$ & $\mathrm{~F}$ & $6293-6357$ & $6286-6350$ & $6277-6345$ & $6277-6345$ & $6269-6333$ & $6268-6333$ \\
\hline $\operatorname{trnF}$ & $\mathrm{R}$ & $6371-6437$ & $6364-6430$ & $6354-6420$ & $6354-6420$ & $6346-6412$ & $6346-6412$ \\
\hline nad5 & $\mathrm{R}$ & $6442-8181$ & $6435-8174$ & $6425-8167$ & $6425-8167$ & $6416-8158$ & $6416-8158$ \\
\hline $\operatorname{trnH}$ & $\mathrm{R}$ & $8182-8246$ & $8175-8239$ & $8168-8231$ & $8168-8231$ & $8159-8226$ & $8159-8226$ \\
\hline nad4 & $\mathrm{R}$ & $8247-9585$ & $8240-9578$ & $8232-9570$ & $8232-9570$ & $8227-9565$ & $8227-9565$ \\
\hline $\operatorname{nad} 41$ & $\mathrm{R}$ & $9620-9913$ & 9611-9904 & $9602-9895$ & $9602-9895$ & $9604-9897$ & $9604-9897$ \\
\hline $\operatorname{trnT}$ & $\mathrm{F}$ & 9918-9982 & 9909-9973 & 9900-9964 & 9900-9964 & 9905-9970 & 9905-9969 \\
\hline $\operatorname{trn} \mathrm{P}$ & $\mathrm{R}$ & 9983-10047 & 9974-10038 & 9965-10029 & $9965-10029$ & 9971-10035 & 9970-10034 \\
\hline nad6 & $\mathrm{F}$ & $10056-10586$ & $10047-10577$ & $10038-10568$ & $10038-10568$ & $10044-10574$ & $10043-10573$ \\
\hline cob & $\mathrm{F}$ & $10590-11738$ & 10581-11729 & $10574-11722$ & $10574-11722$ & $10579-11727$ & $10578-11726$ \\
\hline $\operatorname{trnS}(\mathrm{UCN})$ & $\mathrm{F}$ & $11737-11802$ & $11728-11793$ & $11726-11791$ & $11726-11791$ & $11731-11797$ & $11730-11796$ \\
\hline nad1 & $\mathrm{R}$ & $11802-12755$ & 11793-12746 & $11791-12744$ & $11791-12744$ & $11797-12750$ & 11796-12749 \\
\hline $\operatorname{trnL}(\mathrm{CUN})$ & $\mathrm{R}$ & $12757-12827$ & $12748-12818$ & $12746-12813$ & $12746-12813$ & $12752-12820$ & $12751-12819$ \\
\hline $\mathrm{rrnL}$ & $\mathrm{R}$ & $12828-14210$ & 12819-14204 & $12814-14220$ & $12814-14220$ & $12821-14253$ & $12820-14253$ \\
\hline $\operatorname{trn} \mathrm{V}$ & $\mathrm{R}$ & $14211-14275$ & $14205-14268$ & $14221-14286$ & $14221-14286$ & 14254-14319 & 14254-14319 \\
\hline $\mathrm{rrnS}$ & $\mathrm{R}$ & $14276-15058$ & $14269-15051$ & $14287-15062$ & $14287-15063$ & $14320-15101$ & $14320-15100$ \\
\hline AT region & $\mathrm{F}$ & $15059-15377$ & $15052-15370$ & $15063-15381$ & $15064-15382$ & $15102-15417$ & $15101-15417$ \\
\hline
\end{tabular}




\section{Table 3(on next page)}

Start codon and stop codon of 13 protein coding genes in 6 Dendrolimus species.

Table 3 Start codon and stop codon of 13 protein coding genes in six Dendrolimus species. 
1 Table 3 Start codon and stop codon of 13 protein coding genes in six Dendrolimus species.

\begin{tabular}{|c|c|c|c|c|c|c|c|c|c|c|c|c|c|}
\hline Samples & nad2 & cox1 & $\operatorname{cox} 2$ & atp8 & atp6 & $\operatorname{cox} 3$ & nad3 & nad5 & nad4 & nad4l & nad6 & cob & nad1 \\
\hline D. & ATT/TA & $\mathrm{CGA} /$ & ATA/T & ATC/TA & ATG/TA & ATG/TA & ATC/TA & ATT/TA & ATG/ & ATG/TA & ATA/TA & ATG/TA & ATG/TA \\
\hline spectabilis02 & $\mathrm{A}$ & $\mathrm{T}$ & & $\mathrm{A}$ & $\mathrm{A}$ & $\mathrm{A}$ & & $\mathrm{A}$ & $\mathrm{T}$ & $\mathrm{A}$ & $\mathrm{A}$ & A & $\mathrm{A}$ \\
\hline$D$. & ATT/TA & $\mathrm{CGA} /$ & ATA/T & ATC/TA & ATG/TA & ATG/TA & ATC/TA & ATT/TA & ATG/ & ATG/TA & ATA/TA & ATG/TA & ATG/TA \\
\hline spectabilis13 & $\mathrm{A}$ & $\mathrm{T}$ & & A & $\mathrm{A}$ & $\mathrm{A}$ & & $\mathrm{A}$ & $\mathrm{T}$ & A & $\mathrm{A}$ & $\mathrm{A}$ & $\mathrm{A}$ \\
\hline$D$. & ATT/TA & CGA/ & ATA/T & ATT/TA & ATG/TA & ATG/TA & ATG/TA & ATT/TA & ATG/ & ATG/TA & ATA/TA & ATG/TA & ATG/TA \\
\hline tabulaeformis & A & $\mathrm{T}$ & & A & A & A & & A & $\mathrm{T}$ & A & A & A & A \\
\hline \multicolumn{14}{|l|}{06} \\
\hline$D$. & ATT/TA & CGA/ & ATA/T & ATC/TA & ATG/TA & ATG/TA & $\mathrm{ATT} / \mathrm{TA}$ & ATT/TA & ATG/ & ATG/TA & ATA/TA & ATG/TA & ATG/TA \\
\hline tabulaeformis & A & $\mathrm{T}$ & & A & A & A & & A & $\mathrm{T}$ & A & A & A & A \\
\hline \multicolumn{14}{|l|}{38} \\
\hline$D$. & ATT/TA & $\mathrm{CGA} /$ & ATA/T & ATT/TA & ATG/TA & ATG/TA & ATG/TA & ATT/TA & ATG/ & ATG/TA & ATA/TA & ATG/TA & ATG/TA \\
\hline punctatus04 & A & $\mathrm{T}$ & & A & A & A & & A & $\mathrm{T}$ & A & A & A & A \\
\hline$D$. & ATT/TA & CGA/ & ATA/T & ATT/TA & ATG/TA & ATG/TA & ATA/TA & ATT/TA & ATG/ & ATG/TA & ATA/TA & ATG/TA & ATG/TA \\
\hline punctatus05 & A & $\mathrm{T}$ & & A & A & A & & A & $\mathrm{T}$ & A & A & A & A \\
\hline$D$. & ATT/TA & $\mathrm{CGA} /$ & ATA/T & ATT/TA & ATG/TA & ATG/TA & ATG/TA & ATT/TA & ATG/ & ATG/TA & ATA/TA & ATG/TA & ATG/TA \\
\hline punctatus_ws & A & $\mathrm{T}$ & & A & A & A & & A & $\mathrm{T}$ & A & A & A & A \\
\hline \multicolumn{14}{|l|}{03} \\
\hline$D$. & ATT/TA & $\mathrm{CGA} /$ & $\mathrm{ATA} / \mathrm{T}$ & ATT/TA & ATG/TA & ATG/TA & ATG/TA & ATT/TA & ATG/ & ATG/TA & ATA/TA & ATG/TA & ATG/TA \\
\hline punctatus_ws & A & $\mathrm{T}$ & & A & A & A & & A & $\mathrm{T}$ & A & A & A & A \\
\hline \multicolumn{14}{|l|}{06} \\
\hline \multirow[t]{2}{*}{ D. kikuchii12 } & ATT/TA & CGA/ & ATA/T & ATA/TA & ATG/TA & ATG/TA & ATT/TA & ATA/TA & ATG/ & ATG/TA & ATA/TA & ATG/TA & GTG/TA \\
\hline & A & $\mathrm{T}$ & & A & A & A & A & A & $\mathrm{T}$ & A & A & A & A \\
\hline \multirow[t]{2}{*}{ D. kikuchii22 } & ATT/TA & $\mathrm{CGA} /$ & ATA/T & ATA/TA & ATG/TA & ATG/TA & ATT/TA & ATA/TA & ATG/ & ATG/TA & ATA/TA & ATG/TA & GTG/TA \\
\hline & A & $\mathrm{T}$ & & A & A & A & A & A & $\mathrm{T}$ & A & A & A & A \\
\hline \multirow[t]{2}{*}{ D. houi05 } & ATT/TA & CGA/ & ATA/TA & ATT/TA & ATG/TA & ATG/TA & $\mathrm{ATT} / \mathrm{T}$ & ATT/TA & ATG/ & ATG/TA & ATA/TA & ATG/TA & ATG/TA \\
\hline & A & $\mathrm{T}$ & G & A & A & A & & A & $\mathrm{T}$ & A & A & A & A \\
\hline D. houi11 & ATT/TA & $\mathrm{CGA} /$ & ATA/TA & ATT/TA & ATG/TA & ATG/TA & $\mathrm{ATT} / \mathrm{T}$ & ATT/TA & ATG/ & ATG/TA & ATA/TA & ATG/TA & ATG/TA \\
\hline
\end{tabular}




\begin{tabular}{lllllllllllll} 
A & T & G & A & A & A & & A & T & A & A & A & A \\
ATC/TA & CGA/ & ATA/T & ATT/TA & ATG/TA & ATG/TA & ATC/TA & ATT/TA & ATG/ & ATG/TA & ATA/TA & ATG/TA & ATG/TA \\
A & T & & A & A & A & A & A & T & A & A & A & A \\
ATC/TA & CGA/ & ATA/T & ATT/TA & ATG/TA & ATG/TA & ATC/TA & ATT/TA & ATG/ & ATG/TA & ATA/TA & ATG/TA & ATG/TA \\
A & T & & A & A & A & A & A & T & A & A & A & A \\
\hline
\end{tabular}




\section{Table 4(on next page)}

Sequence length of non-coding and overlapping regions between two genes among 14 individuals of Dendrolimus species.

Table 4 Sequence length of non-coding and overlapping regions between two genes among 6 species: D. spectabilis, D. tabulaeformis, D. punctatus, D. superans, D. kikuchii and D. houi. 
1 Table 4 Sequence length of non-coding and overlapping regions between two genes among 14 individuals of Dendrolimus species.

\begin{tabular}{|c|c|c|c|c|c|c|c|c|c|c|c|c|c|c|}
\hline \multirow[b]{2}{*}{ Location* } & \multicolumn{2}{|c|}{ D. spectabilis } & \multicolumn{2}{|c|}{ D. tabulaeformis } & \multicolumn{2}{|c|}{ D. punctatus punctatus } & \multicolumn{2}{|c|}{ D. punctatus wenshanensis } & \multicolumn{2}{|c|}{ D. superans } & \multicolumn{2}{|c|}{ D. kikuchii } & \multicolumn{2}{|c|}{ D. houi } \\
\hline & $\mathrm{CS} 02$ & CS13 & YS06 & YS38 & MW04 & MW05 & WS03 & WS06 & $\begin{array}{c}\text { LY0 } \\
4\end{array}$ & $\begin{array}{c}\text { LY0 } \\
8\end{array}$ & SM12 & SM22 & YN05 & $\begin{array}{c}\text { YN1 } \\
1\end{array}$ \\
\hline $\operatorname{trnM}$-trnI & 3 & 3 & 3 & 3 & 3 & 3 & 3 & 3 & 3 & 4 & 3 & 3 & 1 & 1 \\
\hline trnI-trnQ & -3 & -3 & -3 & -3 & -3 & -3 & -3 & -3 & -3 & -3 & -3 & -3 & -3 & -3 \\
\hline trnQ-nad2 & 58 & 58 & 58 & 58 & 58 & 58 & 58 & 58 & 54 & 54 & 56 & 54 & 55 & 55 \\
\hline nd2-trnW & -2 & -2 & -2 & -2 & -2 & -2 & -2 & -2 & -2 & -2 & -1 & -1 & -2 & -2 \\
\hline $\operatorname{trnW}-\operatorname{trnC}$ & -8 & -8 & -8 & -8 & -8 & -8 & -8 & -8 & -8 & -8 & -8 & -8 & -8 & -8 \\
\hline $\operatorname{trnC}-\operatorname{trnY}$ & 0 & 0 & 0 & 0 & 0 & 0 & 0 & 0 & 0 & 0 & 0 & 0 & 1 & 1 \\
\hline $\operatorname{trnY} Y-\operatorname{cox} 1$ & 25 & 25 & 34 & 34 & 27 & 34 & 34 & 34 & 32 & 32 & 40 & 41 & 28 & 28 \\
\hline $\operatorname{cox} 2-\operatorname{trnK}$ & 0 & 0 & 0 & 0 & 0 & 0 & 0 & 0 & 0 & 0 & 0 & 0 & 1 & 1 \\
\hline $\operatorname{trnK}-\operatorname{trnD}$ & 3 & 3 & 3 & 3 & 3 & 3 & 3 & 3 & 3 & 3 & 0 & 0 & 1 & 1 \\
\hline atp8-atp6 & -7 & -7 & -7 & -7 & -7 & -7 & -7 & -7 & -7 & -7 & -7 & -7 & -7 & -7 \\
\hline atp6-cox3 & 11 & 11 & 15 & 15 & 15 & 14 & 15 & 15 & 12 & 12 & 6 & 8 & 15 & 15 \\
\hline $\operatorname{cox} 3-\operatorname{trnG}$ & 2 & 2 & 2 & 2 & 2 & 2 & 2 & 2 & 2 & 2 & 2 & 2 & 2 & 2 \\
\hline $\operatorname{nad} 3-\operatorname{trn} A$ & 0 & 0 & 0 & 0 & 0 & 0 & 0 & 0 & 4 & 4 & 2 & 2 & 0 & 0 \\
\hline $\operatorname{trn} A-\operatorname{trnR}$ & 20 & 20 & 15 & 15 & 15 & 15 & 15 & 15 & 13 & 13 & 18 & 18 & 9 & 9 \\
\hline $\operatorname{trnR}-\operatorname{trnN}$ & 4 & 4 & 4 & 4 & 4 & 4 & 4 & 4 & 1 & 1 & 21 & 21 & 5 & 5 \\
\hline $\operatorname{trn} N-\operatorname{trn} S(A G N)$ & 18 & 18 & 11 & 11 & 11 & 13 & 11 & 11 & 16 & 16 & 14 & 7 & 25 & 25 \\
\hline $\operatorname{trnS}(\mathrm{AGN})-\operatorname{trnE}$ & -1 & -1 & -1 & -1 & -1 & -1 & -1 & -1 & -1 & -1 & -1 & -1 & -1 & -1 \\
\hline $\operatorname{trnE}-\operatorname{trnF}$ & 8 & 8 & 4 & 4 & 4 & 4 & 4 & 4 & 12 & 12 & 13 & 13 & 8 & 8 \\
\hline trnF-nad5 & 3 & 3 & 2 & 2 & 2 & 3 & 2 & 2 & 3 & 3 & 4 & 4 & 4 & 4 \\
\hline nad4-nd41 & 23 & 23 & 24 & 24 & 24 & 19 & 24 & 24 & 38 & 38 & 34 & 32 & 31 & 31 \\
\hline nad41-trnT & 7 & 7 & 7 & 7 & 7 & 7 & 7 & 7 & 7 & 7 & 4 & 4 & 4 & 4 \\
\hline trnP-nad6 & 8 & 8 & 8 & 8 & 8 & 8 & 8 & 8 & 8 & 8 & 8 & 8 & 8 & 8 \\
\hline nad6-cytb & 4 & 4 & 4 & 4 & 4 & 4 & 4 & 4 & 4 & 4 & 3 & 3 & 5 & 5 \\
\hline cytb-trnS(UCN) & 3 & 3 & 3 & 3 & 3 & 3 & 3 & 3 & 3 & 3 & -2 & -2 & 3 & 3 \\
\hline $\operatorname{trnS}(\mathrm{UCN})-\mathrm{nd} 1$ & -1 & -1 & -1 & -1 & -1 & -1 & -1 & -1 & -1 & -1 & -1 & -1 & -1 & -1 \\
\hline nad1-trnL(CUN) & 1 & 1 & 1 & 1 & 1 & 1 & 1 & 1 & 1 & 1 & 1 & 1 & 1 & 1 \\
\hline
\end{tabular}

2 Location*: Sequence length between two genes, positive value stands for non-coding regions, negative value stands for overlapping regions. 